\title{
Leaf polyphenol profile and SSR-based fingerprinting of new segregant Cynara cardunculus genotypes
}

\author{
Gaetano Pandino ${ }^{1}$, Sara Lombardo ${ }^{1}$, Andrea Moglia ${ }^{2 *}$, Ezio Portis ${ }^{2}$, Sergio Lanteri ${ }^{2}$ and \\ Giovanni Mauromicale ${ }^{1}$
}

${ }^{1}$ Dipartimento di Agricoltura, Alimentazione e Ambiente Università degli Studi di Catania, Catania, Italy
${ }^{2}$ Dipartimento di Scienze Agrarie, Forestali e Alimentari, Università degli Studi di Torino, Grugliasco, Italy

\section{Edited by:}

Jaime Prohens, Universitat

Politècnica de València, Spain

\section{Reviewed by:}

Margherita Irene Beruto, Istituto

Regionale per la Floricoltura, Italy

Pietro Gramazio, COMAV- Instituo de Conservación y Mejora de la

Agrodiversidad Valenciana, Spain

\section{*Correspondence:}

Andrea Moglia, Dipartimento di

Scienze Agrarie, Forestali e

Alimentari, Università degli Studi di

Torino, Largo Paolo Braccini 2,

10095 Grugliasco, Italy

e-mail: andrea.moglia@unito.it
The dietary value of many plant polyphenols lies in the protection given against degenerative pathologies. Their in planta role is associated with the host's defense response against biotic and abiotic stress. The polyphenol content of a given plant tissue is strongly influenced by the growing environment, but is also genetically determined. Plants belonging to the Cynara cardunculus species (globe artichoke and the cultivated and wild cardoon) accumulate substantial quantities of polyphenols mainly mono and di-caffeoylquinic acid (CQA) in their foliage. Transgressive segregation for COA content in an $F_{1}$ population bred from a cross between a globe artichoke and a cultivated cardoon led to the selection of eight segregants which accumulated more CQA in their leaves than did those of either of their parental genotypes. The selections were grown over two seasons to assess their polyphenol profile (CQAs, apigenin and luteolin derivatives and narirutin), and were also fingerprinted using a set of 217 microsatellite markers. The growing environment exerted a strong effect on polyphenol content, but two of the selections were able to accumulate up to an order of magnitude more CQA than either parent in both growing seasons. Since the species is readily vegetatively propagable, such genotypes can be straightforwardly exploited as a source of pharmaceutically valuable compounds, while their SSR-based fingerprinting will allow the genetic identity of clonally propagated material to be easily verified.

\section{Keywords: Cynara cardunculus, genotype, growing season, SSRs analysis, caffeoylquinic acids, flavones}

\section{INTRODUCTION}

Polyphenols are a diverse group of plant secondary metabolites involved in both protection against biotic and abiotic stresses, and in plant growth and reproduction (Friedman, 1997; Bravo, 1998). They represent an important component of the human diet, as many epidemiological studies have demonstrated that their consumption can be related to a decreased incidence or severity of a number of chronic diseases (Jang et al., 1997; Arai et al., 2000; Birt et al., 2001; Miller and Snyder, 2012). This class of molecule is synthesized by the phenylpropanoid pathway, the initial step of which comprises the deamination of $\mathrm{L}$-phenylalanine to form trans-cinnamic acid, a reaction catalyzed by phenylalanine ammonium lyase (PAL). PAL activity (as well as that of other enzymes in the phenylpropanoid pathway) is influenced by a number of environmental factors, both during the plant's growth, the post-harvest storage of its products, and their processing into food or other products (Beckman, 2000; Tomás-Barberán and Espín, 2001; Kalt, 2005; Pandino et al., 2012, 2013a; Ezekiel et al., 2013). However, genotype is also a major determinant of variation in polyphenol content and profile (Mpofu et al., 2006; Farshadfar et al., 2012; Alfaro et al., 2013; Gündüz and Özdemir, 2014).

Abbreviations: CQA, caffeoylquinic acids; CGA, chlorogenic acid.
The Cynara cardunculus complex includes two cultivated taxa [the globe artichoke (var. scolymus) and the cultivated cardoon (var. altilis)], along with their progenitor, the wild cardoon (var. sylvestris). The wild taxon is distributed across the western and central part of the Mediterranean Basin, the Canary Islands and Madeira and in the Americas; var. altilis is a minor crop cultivated mainly in southern Europe (Portis et al., 2005), while var. scolymus is cropped quite extensively both in Mediterranean countries and has recently spread to Americas and to China (http://faostat. fao.org/, 2012). Crosses between members of the three taxa are viable, fertile and highly variable at the phenotypic level (Lanteri et al., 2006). While the major product of the globe artichoke is the edible head, the plants' leaves have been shown to represent a potentially productive source of flavones and caffeoylquinic acids (CQAs), which have various industrial, pharmaceutical and cosmetic applications (Wang et al., 2003; Pinelli et al., 2007; Moglia et al., 2008, 2009; Comino et al., 2009; Lattanzio et al., 2009). Analyses of cloned individuals selected from the autochthonous Sicilian globe artichoke varieties "Violetto di Sicilia" and "Spinoso di Palermo" have shown that leaf polyphenol content is a highly variable trait (Pandino et al., 2011, 2013b,c). Since the first linkage map produced for globe artichoke (Lanteri et al., 2006), a number of other segregating populations have been exploited for genetic mapping (Portis et al., 2012; Martin et al., 2013), based 
on different classes of molecular markers (Acquadro et al., 2005, 2009; Cravero et al., 2005, 2007). The resulting maps were used to identify and locate the major loci controlling the key agronomic traits. Here, the intention was to use a set of segregating progeny derived from a var. scolymus $\times$ var. altilis cross to characterize segregation for leaf polyphenol content, as well as assigning their genotype with respect to a large panel of SSR (microsatellite) loci.

\section{MATERIALS AND METHODS EXPERIMENTAL PLOTS AND SAMPLING}

The experimental field at the University of Catania, Sicily $\left(37^{\circ} 25^{\prime} \mathrm{N} ; 15^{\circ} 30^{\prime} \mathrm{E} ; 10 \mathrm{~m}\right.$ a.s.l.) lies in an area representative of commercial var. scolymus cultivation. The local climate consists of mild and wet winters and hot, dry summers. A segregating population of $94 \mathrm{~F}_{1}$ hybrids, previously described by Portis et al. (2009), along with six clonally propagated plants of each of the var. scolymus genotype "Romanesco C3" (female parent) and the var. altilis genotype "Altilis 41" (male parent), were grown over the 2009-2010 season (hereafter termed “2010"). "Romanesco C3" is late maturing plant, which produces large purple-green heads, while "Altilis 41" was selected for its high biomass yield potential. Following a preliminary screening of leaf polyphenol content, eight transgressive (with respect to CQA production) $F_{1}$ progeny were clonally reproduced from 12 month old plants by transplanting their semi-dormant offshoots ("ovoli"). For each of the eight selected transgressive genotypes, 15 clonally propagated plants were obtained and grown over the 2010-2011 season (hereafter "2011") in plots arranged in the form of a randomized block design with three replications. In early November in both seasons, at a time when each plant bore at least 30 leaves, a sample of about 10 disease-free leaves per replicate per $F_{1}$ individual was harvested and washed in tap water. The leaf material was chopped and blended in a domestic food processor, then freeze-dried, divided into three aliquots and stored at $-20^{\circ} \mathrm{C}$ pending HPLC analysis.

\section{HPLC-BASED SCREENING OF CAFFEOYLQUINIC ACIDS IN THE $\mathrm{F}_{\mathbf{1}}$ PROGENY}

A $50 \mathrm{mg}$ sample of freeze-dried leaf tissue from each of the 94 $\mathrm{F}_{1}$ hybrid plants was suspended in $1.95 \mathrm{~mL}$ 70:30 (v/v) methanol: water and sonicated for $20 \mathrm{~min}$ in a water bath. After centrifugation $(10,000 \times \mathrm{g}$ for $10 \mathrm{~min})$, a $10 \mu \mathrm{L}$ aliquot of the supernatant, derived by filtration through a $0.45 \mu \mathrm{m}$ Anotop 10 filter (Whatman, Maidstone, UK), was injected into an LC-920 device (Varian, Palo Alto, California, USA). The CQA content of the sample was quantified by means of reverse-phase HPLC, using an analytical Luna C18 column $(2 \times 150 \mathrm{~mm}$, particle size $3 \mu \mathrm{m}$, $100 \AA$; Phenomenex, Torrance, California, USA), along with a $2 \times 4 \mathrm{~mm}$ pre-column (Phenomenex), as described by Menin et al. (2010). The mobile phase was a 1:1000 (v/v) mixture of de-gassed glacial acetic acid and ultrapure water (eluant $\mathrm{A}$ ) and a 1:1000 (v/v) mixture of acetic acid and acetonitrile (eluant B). The initial elution solvent was 5\% B, 95\% A, increasing linearly to $35 \% \mathrm{~B}, 65 \% \mathrm{~A}$ over $28 \mathrm{~min}$. The flow rate was $0.5 \mathrm{~mL} \mathrm{~min}-1$ and the eluate was monitored spectrophotometrically at $300 \mathrm{~nm}$ and $330 \mathrm{~nm}$. Molar quantification of mono-and di-CQAs was based on pre-established calibration curves for both 5-O-CQA and 1,5-O-diCQA.

\section{HPLC-BASED CHARACTERIZATION OF POLYPHENOLS PROFILE IN THE SELECTED $F_{\mathbf{1}}$ GENOTYPES}

Polyphenols were then extracted from the selected eight $F_{1}$ progeny as described by Pandino et al. (2010), and subjected to HPLC analysis using a series 1200 instrument (Agilent Technologies, Palo Alto, CA, USA) equipped with ChemStation software (B.03.01) and a diode array detection system. Separations were achieved by passing the samples through a Zorbax Eclipse XDB-C18 column $(4.6 \times 150 \mathrm{~mm} ; 5.0 \mu \mathrm{m}$ particle size), operated at $30^{\circ} \mathrm{C}$, with a $0.2 \mu \mathrm{m}$ stainless steel inline filter. The protocol was adapted from Pandino et al. (2010): the mobile phase comprised 1: $1000(\mathrm{v} / \mathrm{v})$ mixture of formic acid: water (solvent A) and 1: $1000(\mathrm{v} / \mathrm{v})$ mixture of formic acid: acetonitrile (solvent $\mathrm{B}$ ), using a flow rate of $0.5 \mathrm{~mL} \mathrm{~min}^{-1}$. The process began with a mixture of $5 \% \mathrm{~B}, 95 \% \mathrm{~A}$, reaching $10 \%$ $\mathrm{B}$ after $10 \mathrm{~min}, 40 \% \mathrm{~B}$ after $30 \mathrm{~min}$, and keeping constant at $90 \% \mathrm{~B}$ from 50 to $58 \mathrm{~min}$. Chromatograms were recorded at 280, 310, and $350 \mathrm{~nm}$ and the data collected between 200 and $600 \mathrm{~nm}$. Compound identification was based on retention time, UV spectrum, and with reference to compounds identified in var. scolymus by Wang et al. (2003) and Schütz et al. (2004). Molar quantification of each compound was based on calibration curves generated from available standards. CQAs are presented according to the recommended IUPAC numbering system. Apigenin and luteolin conjugates were quantified as apigenin-7-O-glucoside and luteolin-7-O-glucoside, respectively. Each data point represented the means of three independent experiments. Polyphenol contents are expressed as $\mathrm{g} \mathrm{kg}^{-1}$ dry matter (DM).

All reagents and solvents (analytical or HPLC grade) were purchased from VWR (Leighton Buzzard, UK). Apigenin-7-Oglucoside, apigenin, luteolin-7-O-glucoside, luteolin, 5-O-CQA (chlorogenic acid), hesperetin from Extrasynthese (Lyon, France), cynarin (1,3-di-O-CQA) from Roth (Karlsruhe, Germany). A Milli-Q system (Millipore Corp., Bedford, MA, USA) was used to provide ultrapure water.

To evaluate the dry matter (DM) content in selected genotypes, a $100 \mathrm{~g}$ sample of fresh leaf tissue was oven-dried at $65^{\circ} \mathrm{C}$ (Binder, Milan, Italy) until a constant weight had been reached, then re-weighed. Results are expressed as \% of dry matter on fresh weight.

\section{SSR FINGERPRINTING}

DNA was extracted from young leaves of "Romanesco C3" and "Altilis 41 " and the eight selected $\mathrm{F}_{1}$ progeny following the Lanteri et al. (2004) protocol, then used as template for amplification with a set of 217 SSR primer pairs (Acquadro et al., 2005, 2009; Scaglione et al., 2009) which recognize loci distributed over all 17 C. cardunculus chromosomes (Portis et al., 2012, 2014). Each $10 \mu \mathrm{L}$ PCR was based on $7 \mathrm{ng}$ template combined with $1 \mathrm{x}$ PCR buffer, $1 \mathrm{mM} \mathrm{MgCl}_{2}, 0.5 \mathrm{U}$ Taq DNA polymerase (Qiagen Inc., Venlo, Netherlands), $40 \mathrm{nM} 5$ '-labeled (FAM, HEX, or TAMRA) forward primer, $40 \mathrm{nM}$ unlabeled reverse primer and $0.2 \mathrm{mM}$ dNTP. A touchdown cycling regime was applied, consisting of an initial denaturation of $94^{\circ} \mathrm{C} / 2.5 \mathrm{~min}$, followed by nine cycles of 
$94^{\circ} \mathrm{C} / 30 \mathrm{~s}, 63^{\circ} \mathrm{C} / 30 \mathrm{~s}$ (decreasing by $0.7^{\circ} \mathrm{C}$ per cycle), $72^{\circ} \mathrm{C} / 60 \mathrm{~s}$, and 30 further cycles of $94^{\circ} \mathrm{C} / 30 \mathrm{~s}, 57^{\circ} \mathrm{C} / 30 \mathrm{~s}, 72^{\circ} \mathrm{C} / 60 \mathrm{~s}$. Where only weak amplification was achieved, the $\mathrm{MgCl}_{2}$ concentration was raised to $1.5 \mathrm{mM}$ and the final annealing temperature lowered to $55^{\circ} \mathrm{C}$. The amplicons were separated on an ABI3730 capillary DNA sequencer (Applied Biosystem Inc., Foster City, CA, USA). Internal ROX-labeled GS500 size standards were included in each capillary. The SSR data were collected by GeneMapper v3.5 software (Applied Biosystems) and analyzed using the GenAlex Excel package (Peakall and Smouse, 2006). A co-phenetic distance matrix was generated as described by Smouse and Peakall (1999) and used to construct a UPGMA-based dendrogram (Sneath and Sokal, 1973) implemented within the NTSYS software package v2.10 (Rohlf, 1998). The minimum number of SSR loci needed to fully discriminate all individuals was searched within the set of nine most informative SSRs previously identified for the "Romanesco C3" $\times$ "Altilis 41" progeny by Lanteri et al. (2012), on the basis of their distribution in different linkage groups.

\section{STATISTICAL ANALYSIS}

Population means, standard deviations, distribution histograms were calculated using SPSS statistical software. The data were subjected to a One-Way analysis of variance (ANOVA), and means were separated from one another using Tukey's HSD or Fisher's
LSD (least significant difference) test. A Mantel (1967) test was performed to establish correlations between the similarity matrices generated by a SSR subset and the one generated using the complete set of 217 SSRs.

\section{RESULTS AND DISCUSSION VARIATION IN CAFFEOYLQUINIC ACID CONTENT IN THE FULL $F_{1}$ POPULATION}

Analysis of the methanolic extracts showed that the major leaf phenolic compounds present were chlorogenic acid (5-Ocaffeoylquinic acid; 5-O-CQA) and 1,5-O-dicaffeoylquinic acid (1,5-O-diCQA). The content of both these polyphenols contrasted between "Romanesco C3" and "Altilis 41," with the latter containing more of both 5-O-CQA and 1,5-O-diCQA (1.71 and $1.30 \mathrm{~g} \mathrm{~kg}-1 \mathrm{DM}$, respectively) than the former $(0.61$ and $0.16 \mathrm{~g}$ $\mathrm{kg}^{-1} \mathrm{DM}$, respectively) (Table 1). Both the 5-O-CQA and 1,5-OdiCQA content varied continuously across the full $F_{1}$ population (Figure 1), implying polygenic inheritance for both CQAs. A selection of eight of the $F_{1}$ progeny was made on the basis that they harbored a higher CQA content than either parental genotype, as a result of transgressive segregation derived from additive gene action. Similar segregation behavior for 5-O-CQA content has been noted in a population derived from the cross Jacobaea vulgaris $\times$ Jacobaea aquatica (Kirk et al., 2012) as well as in maize (Bushman et al., 2002).

Table 1 | CQA content ( $\mathrm{kg}^{-1}$ DM) of the parental genotypes "C3" ("Romanesco C3"), "A41" ("Altilis 41") and their $\mathrm{F}_{1}$ progeny.

\begin{tabular}{|c|c|c|c|c|c|c|}
\hline \multirow[t]{2}{*}{ Metabolites } & \multicolumn{3}{|c|}{ Parental genotypes } & \multicolumn{3}{|c|}{$F_{1}$ population } \\
\hline & C3 & A41 & $p$-value & Mean & Range & SE \\
\hline 5-O-caffeoylquinic acid & $0.61 \pm 0.13$ & $1.71 \pm 0.32$ & $p \leq 0.05$ & 1.92 & $0.18-5.72$ & 0.11 \\
\hline 1,5-O-dicaffeoylquinic acid & $0.16 \pm 0.05$ & $1.30 \pm 0.19$ & $p \leq 0.05$ & 0.95 & $0.12-7.36$ & 0.10 \\
\hline
\end{tabular}
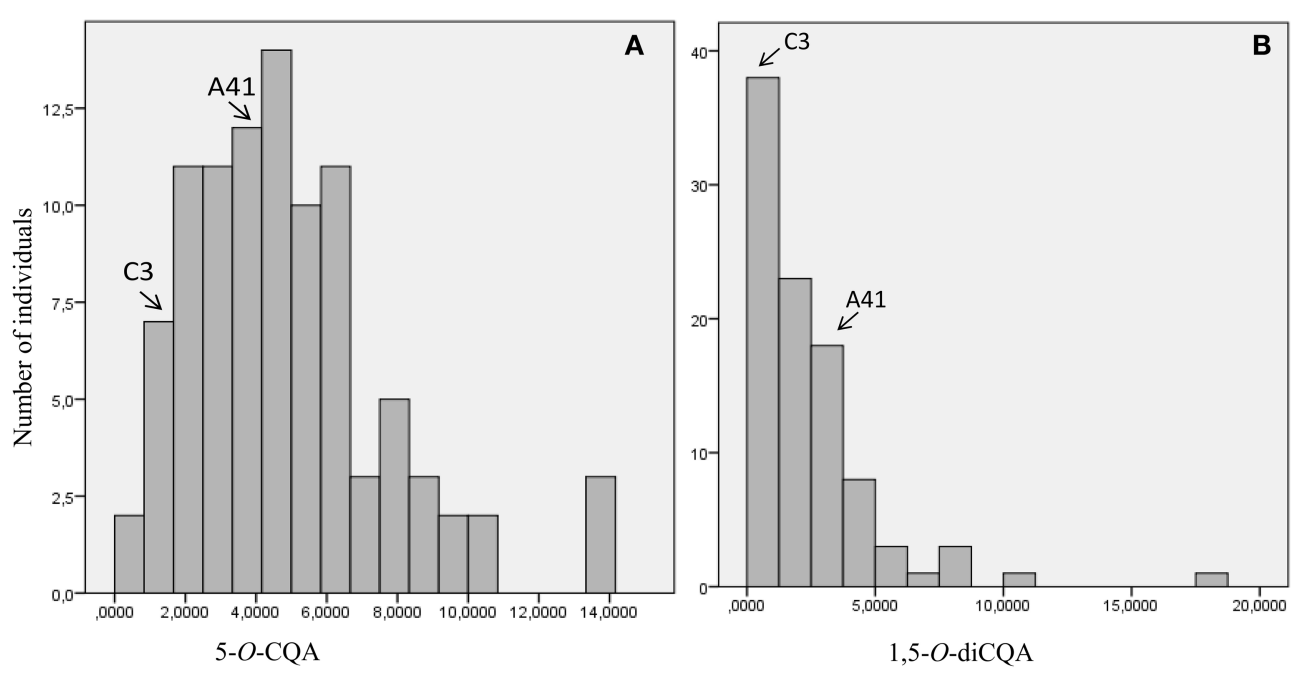

FIGURE 1 | Frequency distribution of CQA content in the $F_{1}$ population derived from the cross "Romanesco C3" $x$ "Altilis 41." (A) 5-O-CQA, (B) 1,5-O-diCQA. The vertical axis indicates the number of individuals per trait value class and the horizontal axis the trait value class. Parental genotypes ("C3": "Romanesco C3," A41: "Altilis 41") are indicated by arrows. 
SEASONAL VARIATION FOR POLYPHENOL PROFILE AND DM CONTENT

As shown in the Table 2, large differences in the content of both total measured polyphenols (TMP) and DM were noted between the 2010 and 2011 seasons. In 2010, TMP ranged from 6.86 to $36.20 \mathrm{~g} \mathrm{~kg}^{-1} \mathrm{DM}$, whereas in 2011 the extremes were 5.12 and
$19.47 \mathrm{~g} \mathrm{~kg}^{-1} \mathrm{DM}$; while DM fluctuated from 15 to $24 \%$ in 2010 , but only from 11 to $16 \%$ in 2011 . The content of luteolin was also strongly season-dependent $\left(2.15-14.75 \mathrm{~g} \mathrm{~kg}^{-1} \mathrm{DM}\right.$ in 2010 and $2.26-8.29 \mathrm{~g} \mathrm{~kg}^{-1} \mathrm{DM}$ in 2011); the coefficient of variation (CV) for this trait was 39\% (Table 3). An even higher CV (93\%)

Table 2 | Total TMP content ( $\mathrm{g} \mathrm{kg}^{-1}$ DM) and DM (\%) of the leaves of plants grown in both 2010 and 2011.

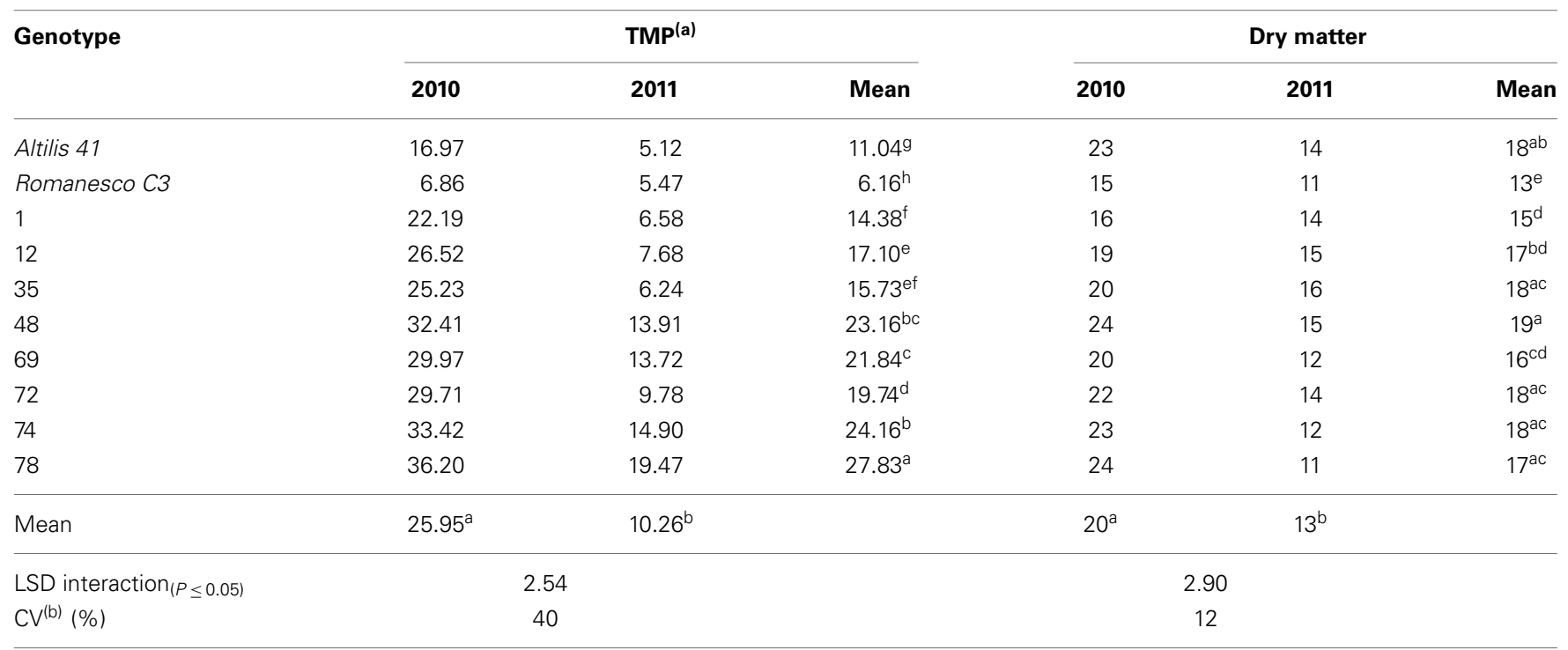

Different letters associated with the set of means indicate significance based on Fisher's protected LSD test $(P \leq 0.05)$.

(a) TMP, total measured polyphenols.

${ }^{(b)} \mathrm{CV}$, coefficient of variation.

Table 3 | The content ( $\mathrm{g} \mathrm{kg}^{-1} \mathrm{DM}$ ) of CQAs, apigenin derivatives, luteolin derivatives and narirutin in the leaves of plants grown in both 2010 and 2011.

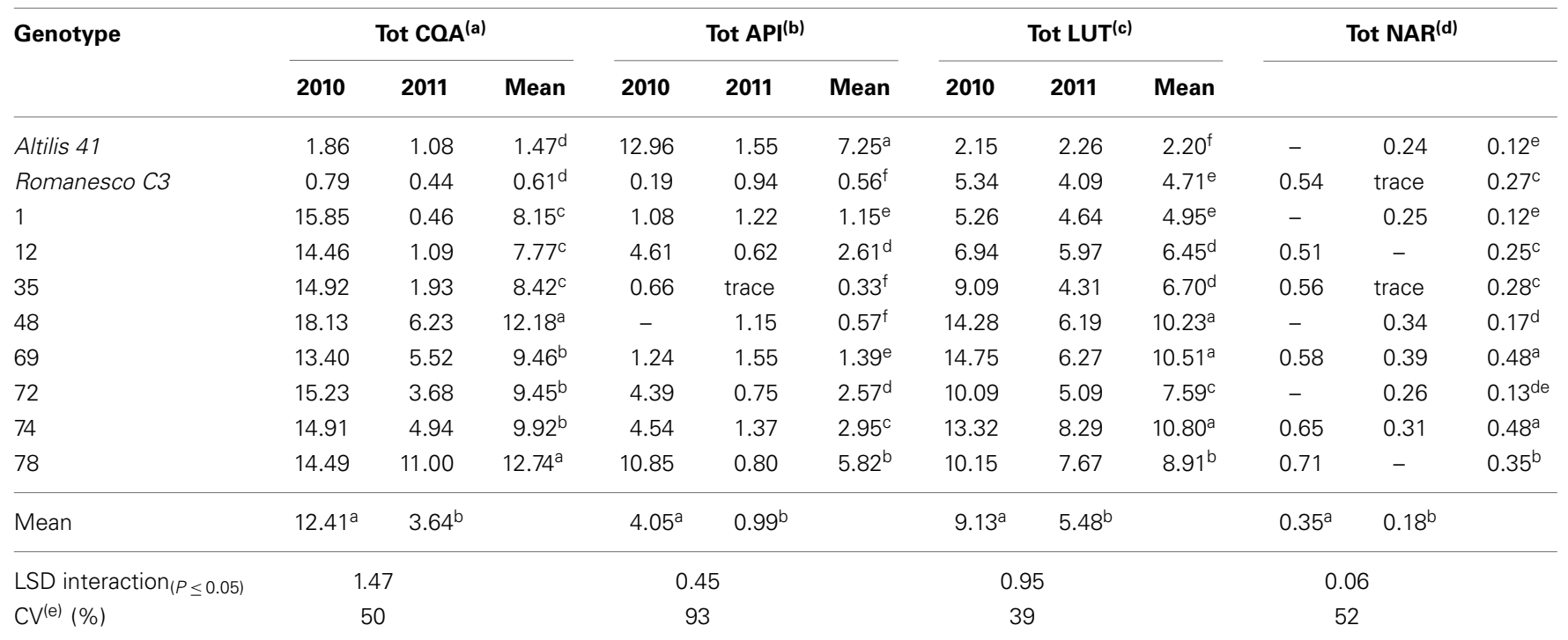

Different letters associated with the set of means indicate significance based on Fisher's protected LSD test ( $P \leq 0.05)$.

(a) Tot CQA, total content of caffeoylquinic acids.

(b) Tot API, total content of apigenin and its derivarives.

(c) Tot LUT, total content of luteolin and its derivarives.

(d) Tot NAR, total content of narirutin.

${ }^{(e)} \mathrm{CV}$, coefficient of variation. 
was noted for the content of apigenin derivatives followed by total content of caffeoylquinic acids and narirutin (CV of 50 and 52\%, respectively) (Table 3). This major season-to-season variability probably reflected considerable differences in the prevailing climatic conditions (Figure 2). Precipitation was $189 \mathrm{~mm}$ in 2010, but $373 \mathrm{~mm}$ in 2011 as a result of rainfall heavily concentrated in a short period of time; despite this, 2010 experienced overall a higher average relative humidity. Air temperature, water availability, relative humidity, and accumulated solar radiation are all known to affect the polyphenol content of a number of fruits and vegetables (Connor et al., 2002; Dumas et al., 2003). The most important environmental factors responsible for the non-genetic determination of polyphenol content in potato are the quantity of rainfall and the relative humidity (Lombardo et al., 2013). In sour jujube fruits, a negative correlation has been established between the volume of annual precipitation and polyphenol content (Sun et al., 2011), while water shortage promotes the accumulation of phenolics in olive (Martinelli et al., 2012). In contrast, a positive correlation has been suggested between precipitation and polyphenol content in both the virgin oil made from fruit of the olive variety "Chétoui" (Temine et al., 2006) and in murtilla fruit (Alfaro et al., 2013). Little is known of the mechanistic basis of how water availability affects secondary metabolite content (Ramakrishna and Ravishankar, 2011), although it is generally
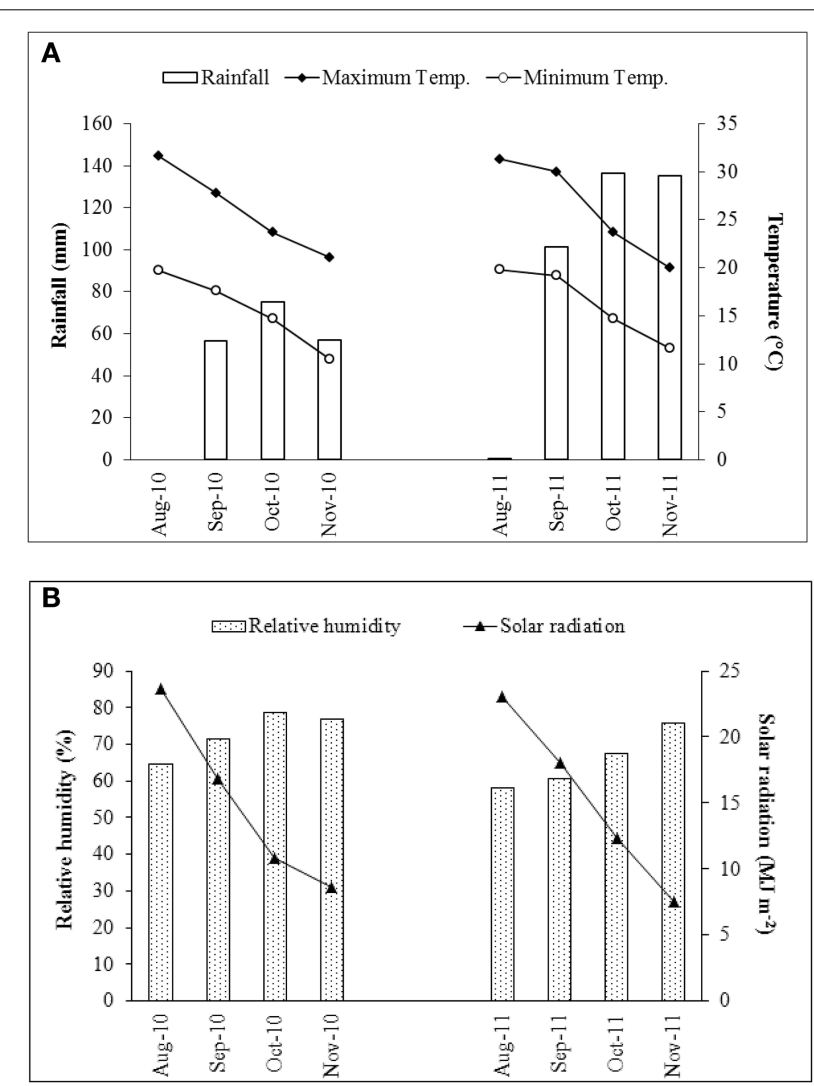

FIGURE 2 | Variation in climatic parameters between the 2010 and 2011 seasons. (A) Rainfall and mean air temperature, (B) relative humidity and solar radiation. assumed that abiotic stress acts to promote polyphenol synthesis (Dixon and Paiva, 1995).

The variation in both TMP and DM content was much greater between the two seasons than between the genotypes, and the genotype $\mathrm{x}$ season interaction was also highly significant (Table 4). The environment on its own explained much of the variation in the content of CQA, TMP and DM, as well as those of apigenin and lutein derivatives and narirutin. A similar experience has been reported by Lombardo et al. (2009), who noted extensive season-to-season variation in TMP content in the heads of a number of var. scolymus varieties, as well as by Zheng et al. (2012) working with Ribes sp. fruit.

\section{POLYPHENOLS IN THE HIGH COA SELECTIONS}

The CQAs contained in larger amounts in both the parents and $\mathrm{F} 1$ individuals were the 5-O-CQA and the 1,5-O-di CQAs, which were the only ones always detectable in the selections over the two growing seasons (Tables 5, 6). Among the selected $\mathrm{F}_{1}$ individuals, selection 78 produced the most 5-O-CQA in both 2010 and 2011 (13.16 and $7.28 \mathrm{~g} \mathrm{~kg}^{-1} \mathrm{DM}$, respectively) (Figure 3), followed by selection 35 in 2010 (12.34 $\left.\mathrm{g} \mathrm{kg}^{-1} \mathrm{DM}\right)$ and selection 69 in 2011 (4.53 $\left.\mathrm{g} \mathrm{kg}^{-1} \mathrm{DM}\right)$ (Tables 5, 6). Selection 1 produced the most 1,5-O-di CQA in $2010\left(9.48 \mathrm{~g} \mathrm{~kg}^{-1} \mathrm{DM}\right)$, followed by selection 48 in the same season $\left(6.64 \mathrm{~g} \mathrm{~kg}^{-1} \mathrm{DM}\right)$.

The most abundant of the luteolin and apigenin derivatives were, respectively, luteolin 7-O-glucoside and apigenin malonyl-glucoside. The leaves of selection 69 harbored the highest content in narirutin, apigenin malonylglucoside, apigenin-7-Oglucuronide, and luteolin-7-O-glucuronide in 2011 (0.39, 0.46, 1.09 , and $\left.4.29 \mathrm{~g} \mathrm{~kg}^{-1} \mathrm{DM}\right)$. It has been noted in potato that although the quantity of polyphenols produced by a given genotype may vary from season to season or from locality to locality, the identity of the compounds present in general does not (Andrè et al., 2009). "Altilis 41" leaf contained more of the apigenin derivatives than any of the other genotypes in both 2010 and

Table 4 | Mean square as absolute value and percentage of total (in brackets) of effects resulting from analysis of variance.

\begin{tabular}{lcrc}
\hline & \multicolumn{3}{c}{ Source of variation } \\
\cline { 2 - 4 } & Genotype (G) & Season (S) & G * S \\
\hline Degree of freedom & 9 & 1 & 9 \\
CQA $^{a}$ & $97^{* * *}(8)^{g}$ & $1154^{* * *}(89)$ & $44^{* * *(3)}$ \\
API $^{b}$ & $33^{* *}(16)$ & $140^{* *}(69)$ & $30^{* *}(15)$ \\
LUT $^{c}$ & $49^{* *}(19)$ & $200^{* *}(76)$ & $14^{* * *(5)}$ \\
NAR $^{d}$ & $0.1^{* * *}(8)$ & $0.5^{* * *}(74)$ & $0.2^{* * *(18)}$ \\
MPe $^{*}$ & $258^{* * *}(7)$ & $3678^{* * *}(92)$ & $46^{* * *(1)}$ \\
DM $^{f}$ & $15^{* * *}(3)$ & $504^{* * *}(94)$ & $14^{* * *(3)}$ \\
\hline
\end{tabular}

${ }^{a}$ CQA, total content of caffeoylquinic acids.

${ }^{b} \mathrm{APl}$, total content of apigenin and its derivatives.

${ }^{c}$ LUT, total content of luteolin and its derivatives.

${ }^{d} N A R$, total content of narirutin.

${ }^{e} \mathrm{MP}$, total content of measured polyphenols.

${ }^{f} D M$, dry matter content.

$g * * *$, Indicate significant at $P \leq 0.001$. 


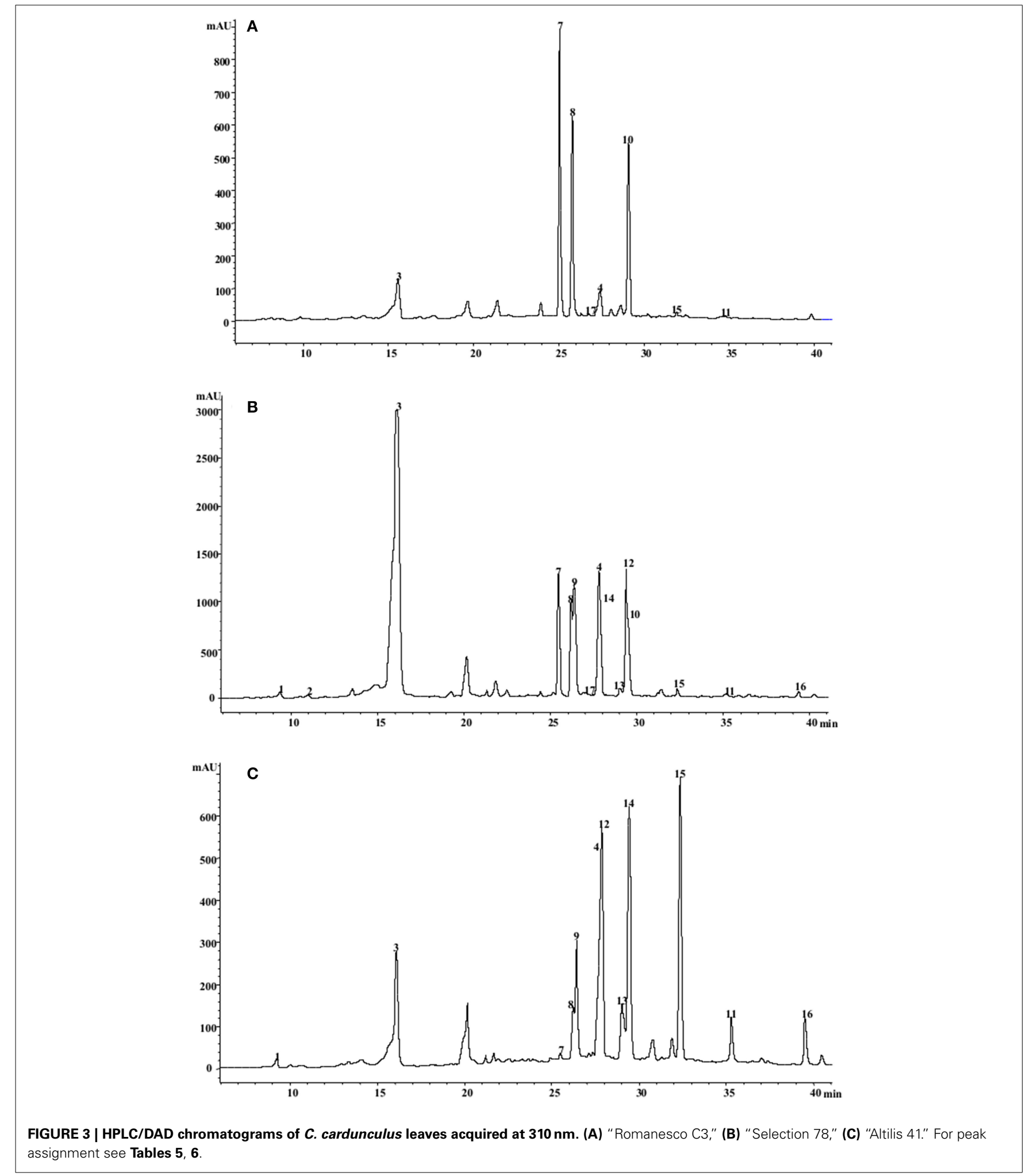

2011, and there was no transgressive segregation for the content of apigenin derivatives among the F1 progeny. Genotype $\times$ environment interactions can often represent a highly important determinant of the phenotypic performance of lines, a problem which confronts crop breeding programmes which seek to identify germplasm which is as widely adapted as possible. With respect to TMP, transgressive segregation ensured that a number of the $F_{1}$ progeny out-performed the parental genotypes in 


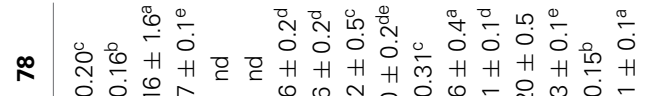

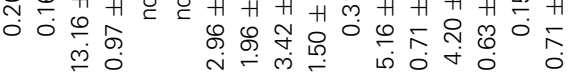

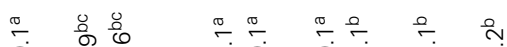

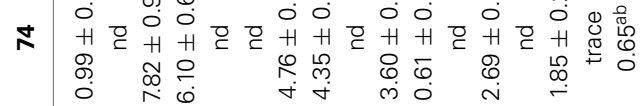

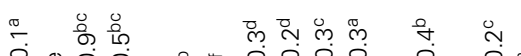

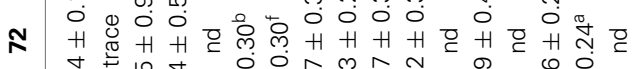

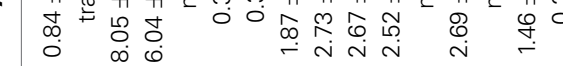

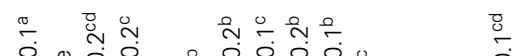

8 H $\begin{aligned} & 0 \\ & \mathbb{0}\end{aligned}$

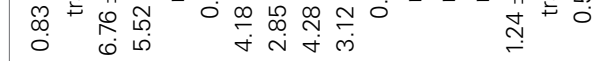

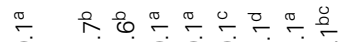

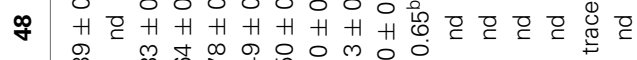

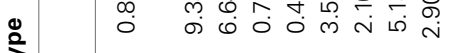

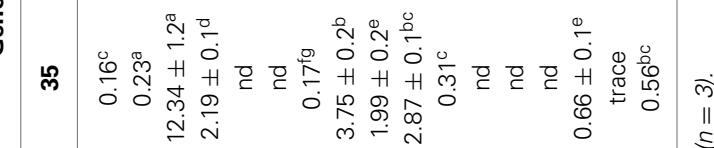

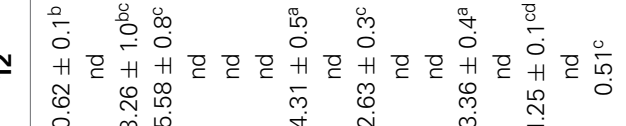

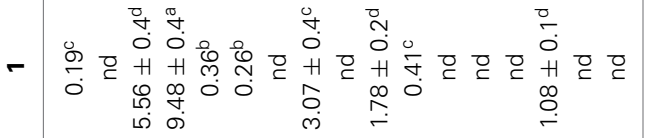

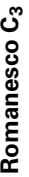

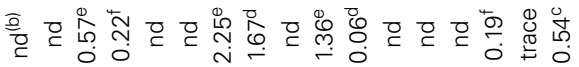

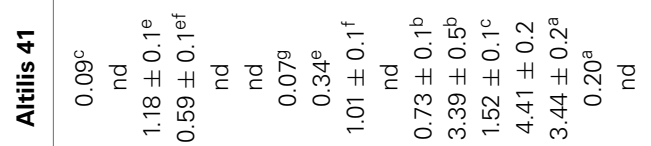

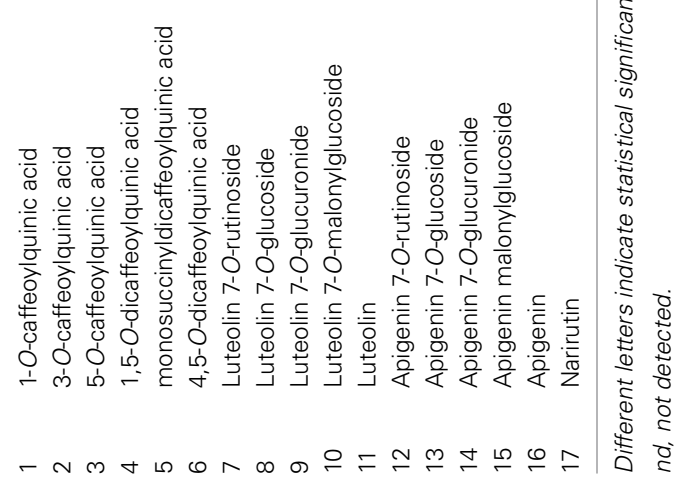

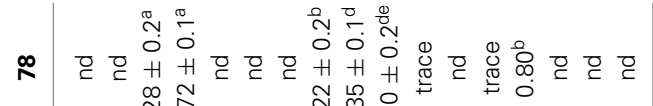

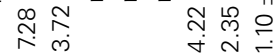

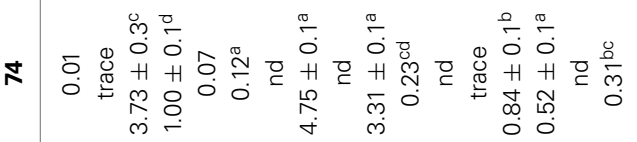

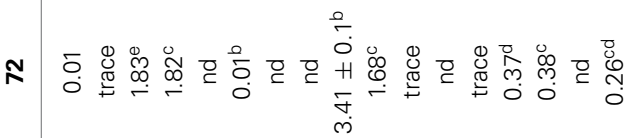

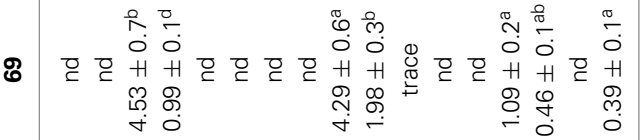

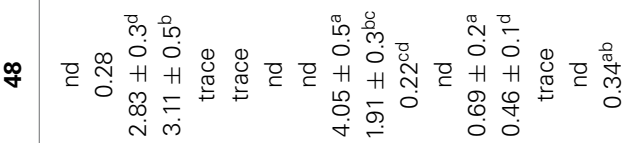

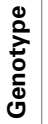

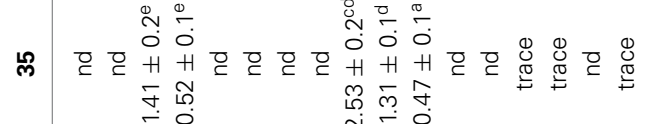

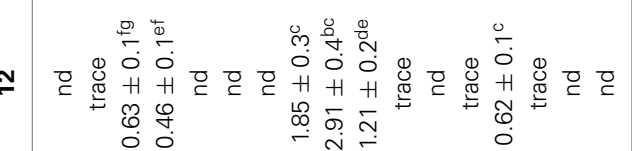

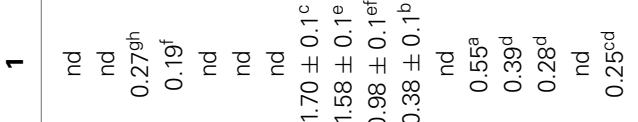

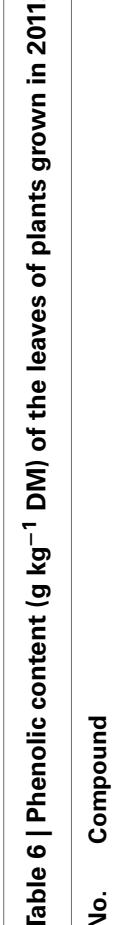

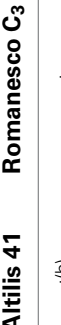

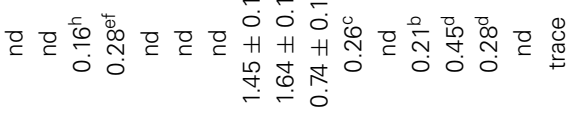

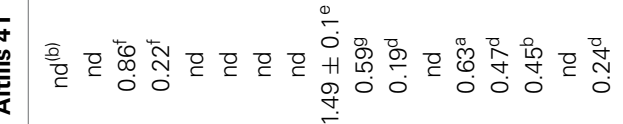

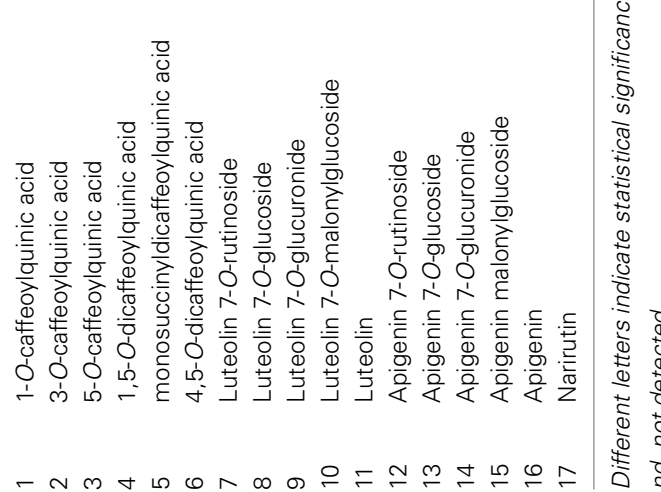




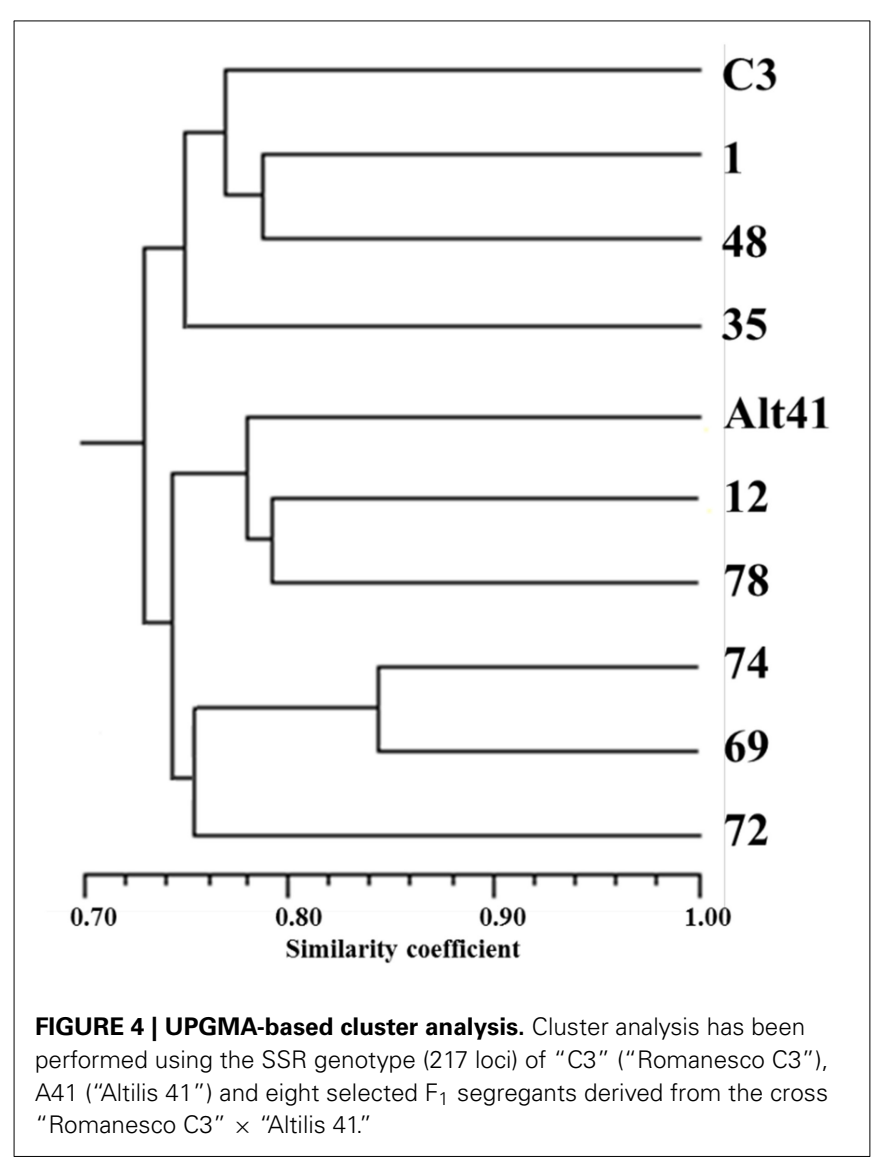

both seasons (Table 2). The less favorable environmental conditions experienced in 2011 strongly reduced TMP by up to a third in selections 1 and 12, and by a quarter in selection 35. However, selections 74 and 78 were less environmentally labile, implying that it should be possible to breed for C. cardunculus germplasm which performs stably with respect to TMP.

\section{GENOTYPIC VARIATION AMONG THE $F_{\mathbf{1}}$ PROGENY}

Out of the set of 217 SSR loci assayed, 59 segregated in a manner consistent with a 1:1:1:1 ratio; of these, 29 involved the segregation of four alleles (both parents being heterozygous for distinct alleles), while the other 30 involved the segregation of three alleles (one parent having the genotype $a b$ and the other $a c$ ). Eight loci segregated 1:2:1 (both parents having the genotype $a b$ ) and at the remaining 150 loci, the ratio was 1:1 (one parent having the genotype $a b$ and the other $a a$ ). The 372 alleles recognized were used to elaborate a phylogeny (Figure 4), in which two major clades were formed, each including one of the two parental genotypes. The most similar pair of individuals (selections 74 and 69) shared $84 \%$ of their alleles. Lanteri et al. (2012) have shown that the progeny of the "Romanesco C3" $\times$ "Altilis 41" cross can be fully discriminated using a set of nine SSRs, each mapping to a different chromosome (Portis et al., 2009). The minimum number of SSR loci needed to fully discriminate between the eight selected $\mathrm{F}_{1}$ progeny was just four (Table 7 ). Interestingly the similarity matrix based on the allelic constitution at these four SSRs
Table 7 | The allelic status at the four SSR loci required to fully discriminate between all eight selected $\mathrm{F}_{1}$ progeny ("C3":

"Romanesco C3," “Alt 41": "Altilis 41").

\begin{tabular}{lcccc}
\hline & $\begin{array}{c}\text { CELMS-23 } \\
\text { (LG 12) }^{*}\end{array}$ & $\begin{array}{c}\text { CELMS-58 } \\
\text { (LG 1) }\end{array}$ & $\begin{array}{c}\text { CELMS-60 } \\
\text { (LG 9) }\end{array}$ & $\begin{array}{c}\text { CMAL-21 } \\
\text { (LG 13) }\end{array}$ \\
\hline C3 & $\mathrm{ab}$ & $\mathrm{ab}$ & $\mathrm{ab}$ & $\mathrm{ab}$ \\
Alt41 & $\mathrm{cd}$ & $\mathrm{cd}$ & $\mathrm{cd}$ & $\mathrm{cd}$ \\
1 & $\mathrm{bd}$ & $\mathrm{ac}$ & $\mathrm{bc}$ & $\mathrm{bc}$ \\
12 & $\mathrm{ad}$ & $\mathrm{bd}$ & $\mathrm{bd}$ & $\mathrm{bc}$ \\
35 & $\mathrm{ac}$ & $\mathrm{bc}$ & $\mathrm{ac}$ & $\mathrm{ac}$ \\
48 & $\mathrm{bc}$ & $\mathrm{bc}$ & $\mathrm{bd}$ & $\mathrm{ad}$ \\
69 & $\mathrm{ad}$ & $\mathrm{bd}$ & $\mathrm{ad}$ & $\mathrm{ad}$ \\
72 & $\mathrm{bc}$ & $\mathrm{ac}$ & $\mathrm{bc}$ & $\mathrm{bd}$ \\
74 & $\mathrm{ad}$ & $\mathrm{bd}$ & $\mathrm{ad}$ & $\mathrm{bc}$ \\
78 & $\mathrm{ad}$ & $\mathrm{bd}$ & $\mathrm{bd}$ & $\mathrm{ac}$ \\
\hline
\end{tabular}

*The mapping position of each SSR is reported in brackets.

among the eight progeny was moderately congruent $(r=0.43)$ with its equivalent based on the full set of 217 SSRs $(r=0.43)$.

As reported by Lanteri et al. (2012), it was possible to fingerprint each individual of the "Romanesco C3" $\times$ "Altilis 41" progeny by applying a set of 9 SSRs (i.e., CELMS-01, -15, -23, -24, $-37,-41,-58,-60$, and CMAL-21) which are dispersed across the linkage groups (Portis et al., 2009, see Supplementary Figure 1) and displayed a four allele segregation.

\section{CONCLUSIONS}

Profiling polyphenols among the $\mathrm{F}_{1}$ segregants from the cross var. scolymus $\times$ var. altilis succeeded in identifying eight transgressive individuals with respect to TMP content. Selections 48 and 78 were of particular interest as characterized by an high biomass production and their accumulation of CQAs was clearly less environmentally labile than that of the other genotypes and the parents. The implication is that there is indeed potential for breeding C. cardunculus as a source of compounds of pharmaceutical and nutraceutical interest. A particular advantage of this crop is that any desirable genotype can be easily vegetatively propagated, either using actively growing or semi-dormant shoots (the latter develop on the underground stem); as an alternative, it has also been shown that plants can be regenerated by in vitro micropropagation. A set of four SSR loci, evenly distributed across the genome is sufficient to unambiguously identify each of the eight transgressive genotypes. The genetic identity of such vegetatively propagated materials can thus be readily established using SSR-based profiling.

\section{AUTHOR CONTRIBUTIONS}

Sergio Lanteri and Giovanni Mauromicale designed and planned the experiments. Gaetano Pandino and Sara Lombardo undertook the crop management and plant sampling, including the HPLC polyphenols profile. Andrea Moglia undertook HPLC preliminary analysis in $\mathrm{F}_{1}$ population. Ezio Portis undertook SSR-based fingerprinting analyses. All the authors drafted the manuscript and approved its final version. 


\section{ACKNOWLEDGMENTS}

This research was partially supported by the Piedmont Region (Italy) through the "ENERCARD_-Valorizzazione energetica di biomasse marginali di cardo e blends residuali mediante pirogassificazione ad alta efficienza."

\section{SUPPLEMENTARY MATERIAL}

The Supplementary Material for this article can be found online at: http://www.frontiersin.org/journal/10.3389/fpls.2014. 00800/abstract

\section{Supplementary Figure 1 | The SSR-based consensus map of \\ C. cardunculus. Marker names are shown to the right of each $L G$, with map distances (in cM) to the left. "r-" and "a-" indicate markers segregating only in, respectively, "Romanesco C3" and "Altilis 41." Segments shaded in red indicate where a pair of LGs has merged as a result of reducing the stringency to LOD 5 . The nine loci needed to obtain specific molecular fingerprinting for each individual of the progeny have been highlighted in red.}

\section{REFERENCES}

Acquadro, A., Lanteri, S., Scaglione, D., Arens, P., Vosman, B., and Portis, E. (2009). Genetic mapping and annotation of genomic microsatellites isolated from globe artichoke. Theor. Appl. Genet. 118, 1573-1587. doi: 10.1007/s00122-0091005-6

Acquadro, A., Portis, E., Lee, D., Donini, P., and Lanteri, S. (2005). Development and characterization of microsatellite markers in Cynara cardunculus L. Genome 48, 217-225. doi: 10.1139/g04-111

Alfaro, S., Mutis, A., Palma, R., Quiroz, A., Seguel, I., and Scheuermann, E. (2013). Influence of genotype and harvest year on polyphenol content and antioxidant activity in murtilla (Ugni molinae Turcz) fruit. J. Soil Sci. Plant Nutr. 13, 67-78. doi: 10.4067/S0718-95162013005000007

Andrè, C. M., Oufir, M., Hoffmann, L., Hausman, J. F., Rogez, H., Larondelle, Y., et al. (2009). Influence of environment and genotype on polyphenol compounds and in vitro antioxidant capacity of native Andean potatoes (Solanum tuberosum L.). J. Food Compos. Anal. 22, 517-524. doi: 10.1016/j.jfca.2008.11.010

Arai, Y., Watanabe, S., Kimira, M., Shimoi, K., Mochizuki, R., and Kinae, N. (2000). Dietary intakes of flavonols, flavones and isoflavones by japanese women and the inverse correlation between quercetin intake and plasma LDL cholesterol concentration. J. Nutr. 130, 2243-2250.

Beckman, C. H. (2000). Phenolic-storing cells: keys to programmed cell death and periderm formation in wilt disease resistance and in general defence responses in plants? Physiol. Mol. Plant Pathol. 57, 101-110. doi: 10.1006/pmpp.2000.0287

Birt, D. F., Hendrich, S., and Wang, W. (2001). Dietary agents in cancer prevention: flavonoids and isoflavonoids. Pharmacol. Ther. 90, 157-177. doi: 10.1016/S0163-7258(01)00137-1

Bravo, L. (1998). Polyphenols: chemistry, dietary sources, metabolism and nutritional significance. Nutr. Rev. 56, 317-333. doi: 10.1111/j.17534887.1998.tb01670.x

Bushman, B. S., Snook, M. E., Gerke, J. P., Szalma, S. J., Berhow, M. A., Houchins, K. E., et al. (2002). Two loci exert major effects on chlorogenic acid synthesis in maize silks Crop Sci. 42, 1669-1678. doi: 10.2135/cropsci2002.1669

Comino, C., Hehn, A., Moglia, A., Menin, B., Bourgaud, F., Lanteri, S., et al. (2009). The isolation and mapping of a novel hydroxycinnamoyltransferase in the globe artichoke chlorogenic acid pathway. BMC Plant Biol. 9:30 doi: 10.1186/14712229-9-30

Connor, A. M., Luby, J. J., and Tong, C. B. S. (2002). Genotypic and environmental variation in antioxidant activity, total phenolic content, and anthocyanin content among blueberry cultivars. J. Amer. Soc. Hort. Sci. 127, 89-97.

Cravero, V., Martin, E., and Cointry, E. (2007). Genetic diversity in Cynara cardunculus determined by sequence-related amplified polymorphism markers. $J$. Amer. Soc. Hortic. Sci. 132, 1-5.

Cravero, V., Picardi, L., and Cointry, E. (2005). An approach for understanding the heredity of two quality traits (head color and tightness) in globe artichoke
(Cynara scolymus L.). Genet. Mol. Biol. 28, 431-434. doi: 10.1590/S141547572005000300016

Dixon, R. A., and Paiva, N. L. (1995). Stress-induced phenylpropanoid metabolism. Plant Cell 7, 1085-1097. doi: 10.1105/tpc.7.7.1085

Dumas, Y., Dadomo, M., Di Lucca, G., and Grolier, P. (2003). Effects of environmental factors and agricultural techniques on antioxidant content of tomatoes. J. Sci. Food Agric. 83, 369-382. doi: 10.1002/jsfa.1370

Ezekiel, R., Singh, N., Sharma, S., and Kaur, A. (2013). Beneficial phytochemicals in potato - a review. Food Res. Int. 50, 487-496. doi: 10.1016/j.foodres.2011.04.025

Farshadfar, E., Mohammadi, R., Rasoli, V., and Khoshakhlagh, F. (2012). Chromosomal localization of the genes controlling phenotypic stability in rye using GGE-biplot. Ann. Biol. Res. 3, 1345-1356.

Friedman, M. (1997). Chemistry, biochemistry, and dietary role of potato polyphenols. A Rev. J. Agric. Food Chem. 45, 1523-1540. doi: 10.1021/jf960900s

Gündüz, K., and Özdemir, E. (2014). The effects of genotype and growing conditions on antioxidant capacity, phenolic compounds, organic acid and individual sugars of strawberry. Food Chem. 155, 298-303. doi: 10.1016/j.foodchem.2014.01.064

Jang, M., Cai, L., Udeani, G. O., Slowing, K. V., Thomas, C. F., Beecher, C. W. W., et al. (1997). Cancer chemopreventive activity of resveratrol, a natural product derived from grapes. Science 275, 218-220. doi: 10.1126/science.275.5297.218

Kalt, W. (2005). Effects of production and processing factors on major fruit and vegetables antioxidants. J. Food Sci. 70, 11-19. doi: 10.1111/j.13652621.2005.tb09053.x

Kirk, H., Cheng, D., Choi, Y. H., Vrieling, K., and Klinkhamer, P. G. L. (2012). Transgressive segregation of primary and secondary metabolites in F2 hybrids between Jacobaea aquatica and J. vulgaris. Metabolomics 8, 211-219. doi: 10.1007/s11306-011-0301-8

Lanteri, S., Acquadro, A., Comino, C., Mauro, R., Mauromicale, G., and Portis, E. (2006). A first linkage map of globe artichoke (Cynara cardunculus var. scolymus L.) based on AFLP, S-SAP, M-AFLP and micro satellite markers. Theor. Appl. Genet. 112, 1532-1542. doi: 10.1007/s00122-006-0256-8

Lanteri, S., Portis, E., Acquadro, A., Mauro, R. P., and Mauromicale, G. (2012). Morphology and SSR fingerprinting of newly developed Cynara cardunculus genotypes exploitable as ornamentals. Euphytica 184, 311-321. doi: 10.1007/s10681-011-0509-8

Lanteri, S., Saba, E., Cadinu, M., Mallica, G., Baghino, L., and Portis, E. (2004). Amplified fragment length polymorphism for genetic diversity assessment in globe artichoke. Theor. Appl. Genet. 108, 1534-1544 doi: 10.1007/s00122-0031576-6

Lattanzio, V., Kroon, P., Linsalata, V., and Cardinali, A. (2009). Globe artichoke, a functional food and source of nutraceutical ingredients. J. Funct. Foods 1, 131-144. doi: 10.1016/j.jff.2009.01.002

Lombardo, S., Pandino, G., and Mauromicale, G. (2013). The influence of growing environment on the antioxidant and mineral content of "early" crop potato. J. Food Compos. Anal. 32, 28-35. doi: 10.1016/j.jfca.2013.08.003

Lombardo, S., Pandino, G., Mauro, R., and Mauromicale, G. (2009). Variation of phenolic content in globe artichoke in relation to biological, technical and environmental factors. Ital. J. Agron. 4, 181-189. doi: 10.4081/ija.2009.4.181

Mantel, N. (1967). The detection of disease clustering and a generalized regression approach. Cancer Res. 27, 209-220.

Martin, E., Cravero, V., Portis, E., Scaglione, D., Acquaviva, E., and Cointry, E. (2013). New genetic maps for globe artichoke and wild cardoon and their alignment with an SSR-based consensus map. Mol. Breed. 32, 177-187. doi: 10.1007/s11032-013-9861-9

Martinelli, F., Basile, B., Morelli, G., d'Andria, R., and Tonutti, P. (2012). Effects of irrigation on fruit ripening behavior and metabolic changes in olive. Sci. Horticult. 144, 201-207. doi: 10.1016/j.scienta.2012.07.012

Menin, B., Comino, C., Moglia, A., Dolzhenko, Y., Portis, E., and Lanteri, S. (2010). Identification and mapping of genes related to caffeoylquinic acid synthesis in Cynara cardunculus L. Plant Sci. 179, 338-347. doi: 10.1016/j.plantsci.2010.06.010

Miller, P. E., and Snyder, D. C. (2012). Phytochemicals and cancer risk: a review of the epidemiological evidence. Nutr. Clin. Pract. 27, 599-612. doi: $10.1177 / 0884533612456043$

Moglia, A., Comino, C., Portis, E., Acquadro, A., De Vos, R. C. H., Beekwilder, J., et al. (2009). Isolation and mapping of a C3'H gene (CYP98A49) from globe artichoke, and its expression upon UV-C stress. Plant Cell Rep. 28, 963-974. doi: 10.1007/s00299-009-0695-1 
Moglia, A., Lanteri, S., Comino, C., Acquadro, A., De Vos, R., and Beekwilder, J. (2008). Stress-induced biosynthesis of dicaffeoylquinic acids in globe artichoke. J. Agric. Food Chem. 56, 8641-8649. doi: 10.1021/jf801653w

Mpofu, A., Sapirstein, H. D., and Beta, T. (2006). Genotype and environmental variation in phenolic content, phenolic acid composition, and antioxidant activity of hard spring wheat. J. Agric. Food Chem. 54, 1265-1270. doi: $10.1021 /$ jf052683d

Pandino, G., Courts, F. L., Lombardo, S., Mauromicale, G., and Williamson, G. (2010). Caffeyolquinic acids and flavonoids in the immature inflorescence of globe artichoke, wild and cultivated cardoon (Cynara cardunculus L.). J. Agric. Food Chem. 58, 1026-1031. doi: 10.1021/jf903311j

Pandino, G., Lombardo, S., Lo Monaco, A., and Mauromicale, G. (2013a). Variation of polyphenols profile in globe artichoke plant during the harvest time. Acta Hort. 983, 407-413.

Pandino, G., Lombardo, S., Lo Monaco, A., and Mauromicale, G. (2013c). Choice of time of harvest influences the polyphenol profile of globe artichoke. J. Funct. Food 5, 1822-1828. doi: 10.1016/j.jff.2013.09.001

Pandino, G., Lombardo, S., and Mauromicale, G. (2011). Chemical and morphological characteristics of new clones and commercial varieties of globe artichoke (Cynara cardunculus var. scolymus). Plant Foods Hum. Nutr. 66, 291-297. doi: 10.1007/s11130-011-0247-z

Pandino, G., Lombardo, S., and Mauromicale, G. (2013b). Globe artichoke leaves and floral stems as a source of bioactive compounds. Ind. Crops Prod. 44, 44-49. doi: 10.1016/j.indcrop.2012.10.022

Pandino, G., Lombardo, S., Williamson, G., and Mauromicale, G. (2012). Polyphenol profile and content in wild and cultivated Cynara cardunculus L.: a review. Ital. J. Agron. 7, 254-261. doi: 10.4081/ija.2012.e35

Peakall, R., and Smouse, P. (2006). GENALEX 6: genetic analysis in Excel. Population genetic software for teaching and research. Mol. Ecol. Notes 6, 288-295. doi: 10.1111/j.1471-8286.2005.01155.x

Pinelli, P., Agostini, F., Comino, C., Lanteri, S., Portis, E., and Romani, A. (2007). Simultaneous quantification of caffeoyl esters and flavonoids in wild and cultivated cardoon leaves. Food Chem. 105, 1695-1701. doi: 10.1016/j.foodchem.2007.05.014

Portis, E., Barchi, L., Acquadro, A., Macua, J., and Lanteri, S. (2005). Genetic diversity assessment in cultivated cardoon by AFLP (Amplified Fragment Length Polymorphism) and microsatellite markers. Plant Breed. 124, 299-304. doi: 10.1111/j.1439-0523.2005.01098.x

Portis, E., Mauromicale, G., Mauro, R., Acquadro, A., Scaglione, D., and Lanteri, S. (2009). Construction of a reference molecular linkage map of globe artichoke (Cynara cardunculus var. scolymus). Theor. Appl. Genet. 120, 59-70. doi: 10.1007/s00122-009-1159-2

Portis, E., Mauro, R. P., Barchi, L., Acquadro, A., Mauromicale, G., and Lanteri, S. (2014). Mapping yield-associated trait QTL in globe artichoke. Mol. Breed. 34, 615-630. doi: 10.1007/s11032-014-0061-z

Portis, E., Scaglione, D., Acquadro, A., Mauromicale, G., Mauro, R., Knapp, S., et al. (2012). Genetic mapping and identification of QTL for earliness in the globe artichoke/cultivated cardoon complex. BMC Res. Notes 5:252. doi: 10.1186/1756-0500-5-252

Ramakrishna, A., and Ravishankar, G. A. (2011). Influence of abiotic stress signals on secondary metabolites in plants. Plant Signal. Behav. 6, 1720-1731. doi: 10.4161/psb.6.11.17613
Rohlf, F. J. (1998). NTSYSpc Version 2.0: User Guide. New York, NY: Applied Biostatistics Inc.

Scaglione, D., Acquadro, A., Portis, E., Taylor, C. A., Lanteri, S., and Knapp, S. J. (2009). Ontology and diversity of transcript-associated microsatellites mined from globe artichoke EST database. BMC Genomics 10:454. doi: 10.1186/14712164-10-454

Schütz, K., Kammerer, D., Carle, R., and Schieber, A. (2004). Identification and quantification of caffeoylquinic acids and flavonoids from artichoke (Cynara scolymus L.) heads, juice, and pomace by HPLC-DAD-ESI/MS ${ }^{n}$. J. Agric. Food Chem. 52, 4090-4096. doi: 10.1021/jf049625x

Smouse, P., and Peakall, R. (1999). Spatial autocorrelation analysis of individual multiallele and multilocus genetic structure. Heredity 82, 561-573. doi: 10.1038/sj.hdy.6885180

Sneath, P. H. A., and Sokal, R. R. (1973). Numerical Taxonomy-The Principles and Practice of Numerical Classification. San Francisco:W. H. Freeman.

Sun, Y.-F., Liang, Z.-S., Shan, C.-J., Viernstein, H., and Unger, F. (2011). Comprehensive evaluation of natural antioxidants and antioxidant potentials in Ziziphus jujuba Mill. var. spinosa (Bunge) Hu ex H. F. Chou fruits based on geographical origin by TOPSIS method. Food Chem. 124, 1612-1619. doi: 10.1016/j.foodchem.2010.08.026

Temine, S. B., Wael, T., Bechir, B., Teila, A., Douja, D., and Mokhatar, Z. (2006). Changes in olive oil quality of Chétoui variety according to origin of plantation. J. Food Lipids 13, 88-99. doi: 10.1111/j.1745-4522.2006.00036.x

Tomás-Barberán, F. A., and Espín, J. C. (2001). Phenolic compounds and related enzymes as determinants of quality in fruit and vegetables. J. Sci. Food Agric. 81, 853-876. doi: 10.1002/jsfa.885

Wang, M., Simon, J. E., Aviles, I. F., He, K., Zheng, Q. Y., and Tadmor, Y. (2003). Analysis of antioxidative phenolic compounds in artichoke (Cynara scolymus L.). J. Agric. Food Chem. 51, 601-608. doi: 10.1021/jf020792b

Zheng, J., Yang, B., Ruusunen, V., Laaksonen, O., Tahvonen, R., Hellsten, J., et al. (2012). Compositional differences of phenolic compounds between black currant (Ribes nigrum L.) cultivars and their response to latitude and weather conditions. J. Agric. Food Chem. 60, 6581-6593. doi: 10.1021/jf3012739

Conflict of Interest Statement: The authors declare that the research was conducted in the absence of any commercial or financial relationships that could be construed as a potential conflict of interest.

Received: 05 November 2014; accepted: 22 December 2014; published online: 21 January 2015.

Citation: Pandino G, Lombardo S, Moglia A, Portis E, Lanteri S and Mauromicale G (2015) Leaf polyphenol profile and SSR-based fingerprinting of new segregant Cynara cardunculus genotypes. Front. Plant Sci. 5:800. doi: 10.3389/fpls.2014.00800

This article was submitted to Crop Science and Horticulture, a section of the journal Frontiers in Plant Science.

Copyright (C) 2015 Pandino, Lombardo, Moglia, Portis, Lanteri and Mauromicale. This is an open-access article distributed under the terms of the Creative Commons Attribution License (CC BY). The use, distribution or reproduction in other forums is permitted, provided the original author (s) or licensor are credited and that the original publication in this journal is cited, in accordance with accepted academic practice. No use, distribution or reproduction is permitted which does not comply with these terms. 